\section{Endoscopic treatment of acute ascending cholangitis in a patient with RouX-en-Y limb obstruction after a Whipple operation}

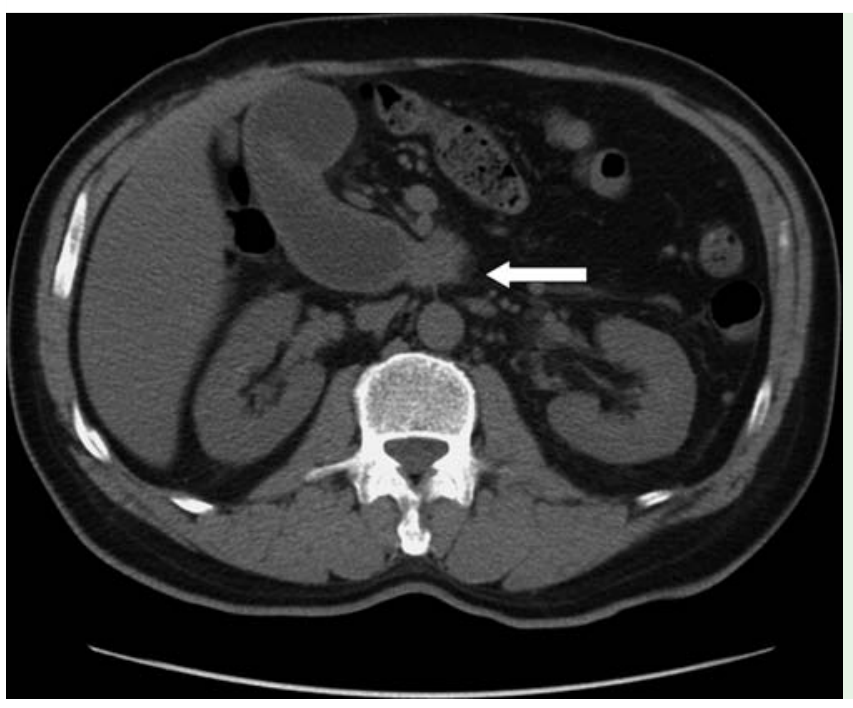

Fig. 1 Computed tomography (CT) scan showed marked dilatation of the Roux-en-Y limb with a soft tissue mass, which was a suspected recurrent pancreatic carcinoma (white arrow).

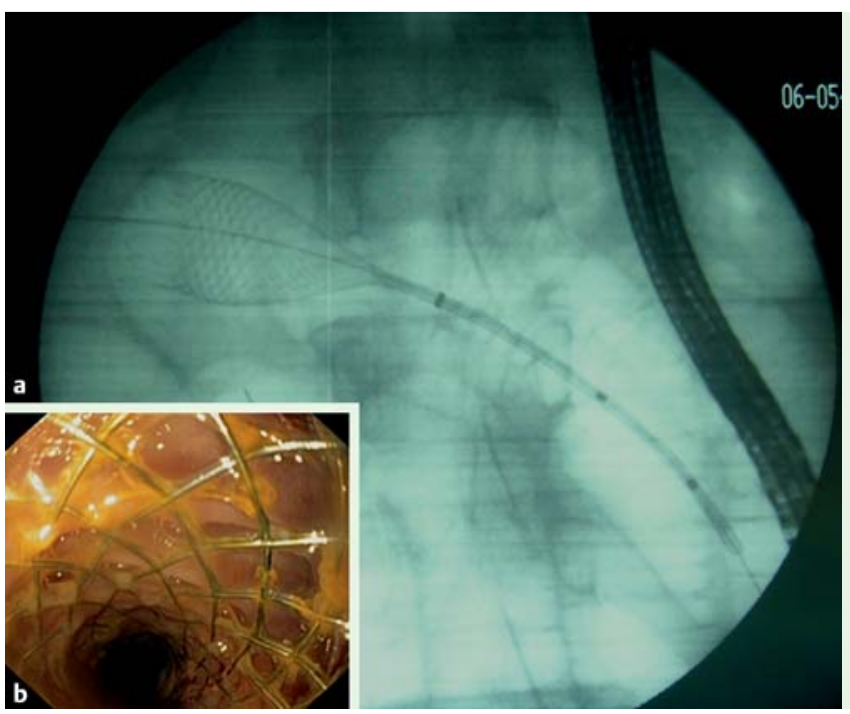

Fig. 3 Self-expandable metallic stent deployed under a fluoroscopic and $\mathbf{b}$ endoscopic controls.

A 60-year-old man was diagnosed with pancreatic head adenocarcinoma. He underwent pancreaticoduodenectomy (Whipple procedure). Four months later he developed obstructive jaundice, high fever, and chills. His total bilirubin level was $2.0 \mathrm{mg} / \mathrm{dL}$ (range $0.3-1.2 \mathrm{mg} / \mathrm{dL}$ ) and alkaline phosphatase was $270 \mathrm{U} / \mathrm{L}$ (range 39-117 U/L). Computed tomography (CT) of the abdomen showed marked dilatation of the afferent limb and a suspected recurrent tumor in the pancreatic area (৫ Fig. 1).
The patient underwent an emergency endoscopy and a guidewire could be passed beyond the obstruction into the proximal part of the afferent limb ( $\bullet$ Fig. 2).

Endoscopic placement of a self-expandable metallic stent (enteral stent, $80 \mathrm{~mm}$; Boston Scientific, Massachusetts, USA) was performed using a therapeutic gastroscope (1TGIF; Olympus Corp., Tokyo, Japan) ( Fig. 3).

After the procedure, the patient's bilirubin normalized and the fever resolved. Plain film of the abdomen revealed a good deployment of the stent ( $\bullet$ Fig. 4).

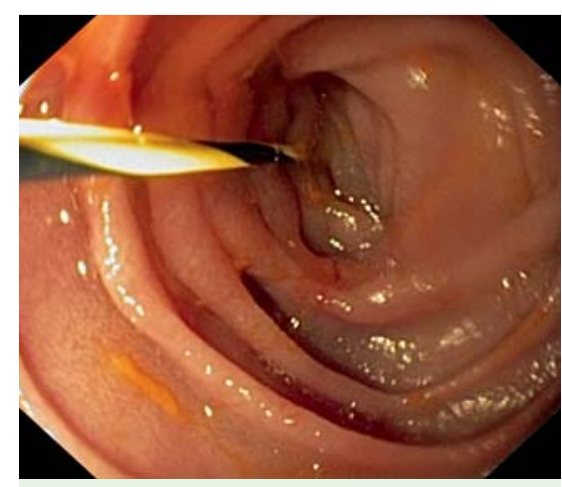

Fig. 2 The endoscopic view revealed the obstructive point, past which the guidewire could be passed into the proximal part.

The patient was discharged 1 week later. He received adjunctive radiotherapy and at the 6-month follow-up remained asymptomatic.

Afferent loop obstruction is a rare complication after the Whipple procedure. In the rare case of complete obstruction, there is a high risk of developing necrosis and perforation. This condition requires immediate intervention. Percutaneous transhepatic drainage $[1,2]$ and surgical drainage $[3,4]$ are alternative management strategies with very high risk in some patients. Endoscopic metallic stent placement [5] is a treatment of choice to avoid an unnecessary and high risk operation. Longterm follow-up data are required to establish its clinical efficacy.

Competing interests: None

Endoscopy_UCTN_Code_TTT_1AR_2AK 


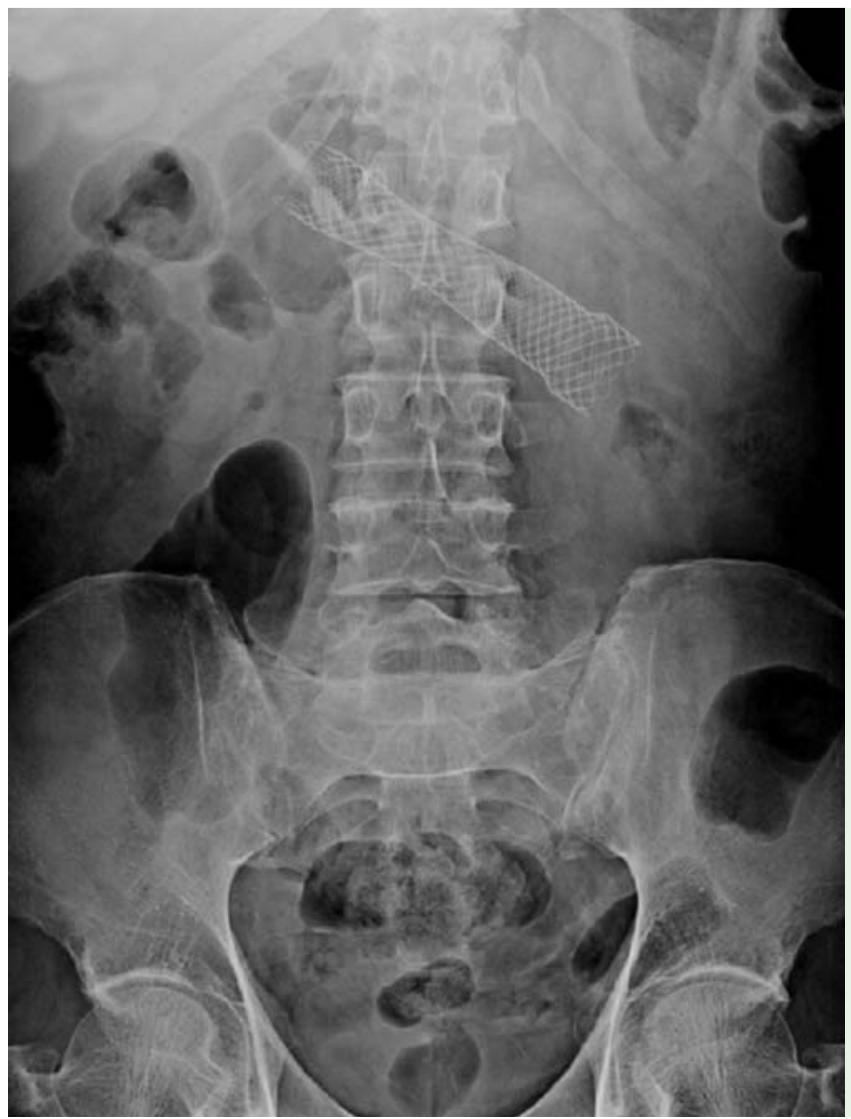

Fig. 4 One day later, plain film of the abdomen demonstrated the metallic stent was placed in a good position.

\section{T. Akaraviputh, A. Trakarnsanga, K. Tolan}

Minimally Invasive Surgery Center, Division of General Surgery, Faculty of Medicine Siriraj Hospital, Mahidol

University, Bangkok, Thailand

\section{References}

1 Yoshida H, Mamada Y, Taniai $N$ et al. Onestep palliative treatment method for obstructive jaundice caused by unresectable malignancies by percutaneous transhepatic insertion of an expandable metallic stent. World J Gastroenterol 2006; 12: 2423-2426

2 Johnsson E, Delle M, Lundell L, Liedman B. Transhepatic placement of an enteral stent to treat jaundice in a tumor recurrence obstructed afferent loop after a Whipple procedure. Dig Surg 2003; 20: 329-331

3 Aimoto T, Uchida E, Nakamura Y et al. Malignant afferent loop obstruction following pancreaticoduodenectomy: report of two cases. J Nippon Med Sch 2006; 73: 226-230

4 Spiliotis J, Karnabatidis D, Vaxevanidou A et al. Acute cholangitis due to afferent loop syndrome after a Whipple procedure: a case report. Cases J 2009; 2: 6339

5 Burdick JS, Garza AA, Magee DJ et al. Endoscopic management of afferent loop syndrome of malignant etiology. Gastrointest Endosc 2002; 55: 602-605

\section{Bibliography}

DOI 10.1055/s-0030-1255978

Endoscopy 2010; 42: E335 -E336

(c) Georg Thieme Verlag KG Stuttgart - New York . ISSN 0013-726X

\section{Corresponding author}

\section{T. Akaraviputh, MD}

Minimally Invasive Surgery Center

Division of General Surgery

Department of Surgery

Faculty of Medicine Siriraj Hospital

Mahidol University

Bangkok 10700

Thailand

Fax: +66-2-412-1370

sitak@mahidol.ac.th 